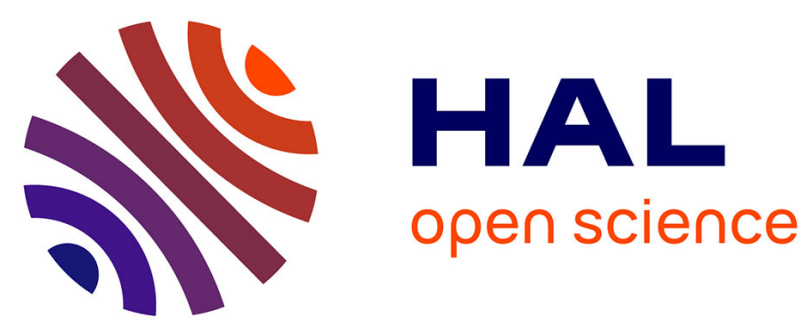

\title{
Topology Controls the Electronic Absorption and Delocalization of Electron Holes in Guanine Quadruplexes
}

Lara Martinez-Fernandez, Akos Banyasz, Dimitra Markovitsi, Roberto Improta

\section{To cite this version:}

Lara Martinez-Fernandez, Akos Banyasz, Dimitra Markovitsi, Roberto Improta. Topology Controls the Electronic Absorption and Delocalization of Electron Holes in Guanine Quadruplexes. Chemistry - A European Journal, 2018, 24 (57), pp.15185 - 15189. 10.1002/chem.201803222 . cea-01934838

\section{HAL Id: cea-01934838 https: / hal-cea.archives-ouvertes.fr/cea-01934838}

Submitted on 23 Oct 2019

HAL is a multi-disciplinary open access archive for the deposit and dissemination of scientific research documents, whether they are published or not. The documents may come from teaching and research institutions in France or abroad, or from public or private research centers.
L'archive ouverte pluridisciplinaire HAL, est destinée au dépôt et à la diffusion de documents scientifiques de niveau recherche, publiés ou non, émanant des établissements d'enseignement et de recherche français ou étrangers, des laboratoires publics ou privés. 


\title{
Topology Controls the Electronic Absorption and Delocalization of Electron Holes in Guanine Quadruplexes
}

\author{
Lara Martínez-Fernández ${ }^{[a]}$ Akos Banyasz ${ }^{[a]}$ Dimitra Markovitsi, ${ }^{*[a]}$ and Roberto Improta ${ }^{*[a, b]}$
}

\begin{abstract}
Guanine quadruplexes (G4) are four-stranded DNA structures involved in biological processes and are promising candidates for potential nanotechnological applications. This study examines how the $\mathbf{G 4}$ topology affects the electronic absorption and the delocalization of electron holes, which play a key role in charge transport and oxidative damage. Combining transient absorption spectroscopy with PCM/TD-DFT calculations both parallel (P) and antiparallel (A) G4 are investigated, which are formed, respectively, by association of four TGGGGT strands and folding of the human telomeric sequence GGG(TTAGGG) 3 . The experimental absorption spectra obtained upon photo-ionization of $\mathbf{A}$ and $\mathbf{P}$ are different. This is explained by the different topology of the two G4, as well as by hole delocalization between two stacked guanines, possible only in $\mathbf{P}^{+}$. The spectral signature of delocalized hole in guanine-rich regions is provided and the chemical physical effects which rule the hole delocalization are discussed.
\end{abstract}

Electron holes in molecular systems play a key role in natural phenomena, such as photosynthesis or oxidative DNA damage, as well as in molecular electronics. The hole may be localized on a single building block of the system or delocalized over several of them. The extent of hole delocalization is a fundamental property which governs charge migration and charge transfer important to many biological and technological processes. Both aspects concern guanine quadruplexes (G4), which are four-stranded structures formed by guanine-rich DNA sequences. They are characterized by vertically stacked tetrads ( $\mathbf{T}$ ) composed of four guanines connected via Hoogsten-type hydrogen bonds. G4, in which the occurrence of hole transport was evidenced, ${ }^{[1]}$ have been correlated, on the one hand, to the oxidative damage of telomeres, ${ }^{[2]}$ and, on the other, proposed as nano-wires for the development of pro-

[a] Dr. L. Martínez-Fernández, Dr. A. Banyasz, Dr. D. Markovitsi, Dr. R. Improta LIDYL, CEA, CNRS, Université Paris-Saclay, 91191 Gif-sur-Yvette (France) E-mail:dimitra.markovitsi@cea.fr

[b] Dr. R. Improta

Istituto di Biostrutture e Bioimmagini, CNR

Via Mezzocannone 16, 80134 Napoli (Italy) E-mail: robimp@unina.it

$\square$ Supporting information and the ORCID identification number(s) for the

(iD) author(s) of this article can be found under: https://doi.org/10.1002/chem.201803222. grammable circuits. ${ }^{[3]}$ Here, we show that hole delocalization in G4 may be affected by the relative orientation of guanines located in different tetrads (Scheme 1). We focus on two prototypical G4 structures: parallel (P), resulting from association of four TGGGGT strands, and antiparallel (A), formed by folding of
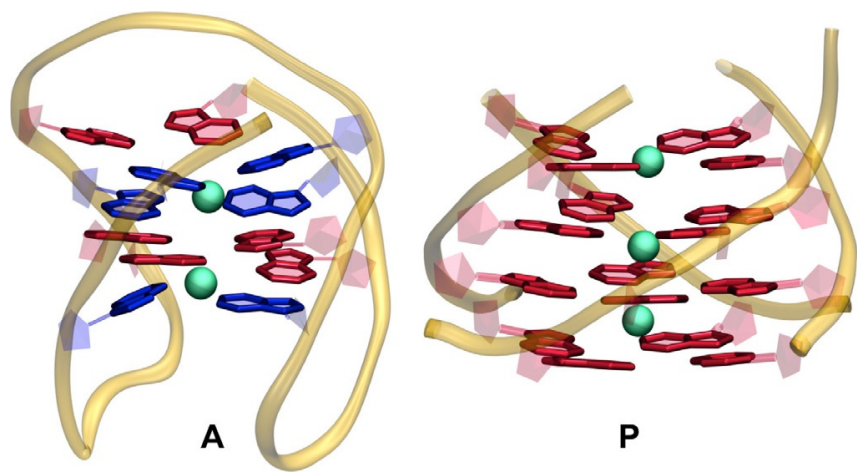

Scheme 1. Antiparallel A (143d.pdb) ${ }^{[6]}$ and parallel $\mathbf{P}(244 \mathrm{~d} . \mathrm{pdb})^{[7]}$ guanine quadruplexes formed by folding of the GGG(TTAGGG) ${ }_{3}$ sequence and association of four TGGGGT strands, both stabilized by $\mathrm{Na}^{+}$ions (green). "anti" guanines, in respect to the glycosidic bond, are represented in red while "syn" guanines in blue. For simplicity adenine and thymine bases are not shown.

the human telomeric sequence GGG(TTAGGG) ${ }_{3}$, both stabilized by $\mathrm{Na}^{+}$ions. Using time-resolved absorption spectroscopy we show that electron holes generated in $\mathbf{P}$ and $\mathbf{A}$ by photo-ionization $^{[4]}$ exhibit different absorption spectra. This observation is interpreted by a thorough computational analysis, combining full quantum mechanical (QM) and mixed $\mathrm{QM} /$ molecular mechanics (QM/MM) calculations, which reveal that the degree of localization is different in A and P. This fundamental difference, together with the specific topology of each G4, accounts for the observed optical behavior. On this ground, we identify the spectral signature of hole-delocalization in $\mathbf{G 4}$ as well as the main structural effects ruling this process.

Experimentally, the electron holes in $\mathbf{G 4}$ were created via photo-ionization by low intensity $5 \mathrm{~ns}$ laser pulses at $266 \mathrm{~nm}$ as described in ref. [4b]. P and A were dissolved in phosphate buffer for which the $\mathrm{pH}$ was adjusted to 3 in order to prevent deprotonation of the guanine cation. ${ }^{[4,5]}$ The steady-state absorption spectra of $\mathrm{G} 4$ at $\mathrm{pH} 3$ were the same as at $\mathrm{pH} 7$ (Figure SI-1) and show that the four-stranded structure is preserved under acidic conditions. Transient absorption signals were recorded on a $90 \mu$ s scale (Figure SI-2). The spectra at $50 \mu \mathrm{s}$ are shown in Figure 1. Under our experimental condi- 


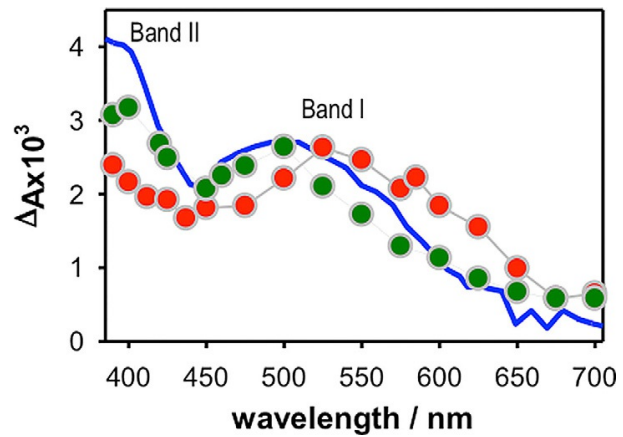

Figure 1. Transient absorption spectra determined at $50 \mu$ for $\mathbf{P}^{+}$(red) and $\mathrm{A}^{+}$(green) using the same excitation intensity $\left(2.2 \mathrm{MW} \mathrm{cm}^{-2}\right)$ at $266 \mathrm{~nm}$. The blue solid line corresponds to the spectrum of the dGMP cation ${ }^{[5 a]}$ arbitrarily normalized. Estimated error: 10\%.

tions only nucleobases undergo one- and two-photon ionization. ${ }^{[4]}$ Moreover, the concentration of ejected electrons is one order of magnitude lower than the $\mathbf{G} 4$ concentration. Therefore, the spectra in Figure 1 correspond to $\mathbf{A}$ and $\mathbf{P}$ bearing only one electron hole, noted as $\mathbf{A}^{+}$and $\mathbf{P}^{+}$. The spectrum of $\mathrm{A}^{+}$is characterized by a band around $500 \mathrm{~nm}$ (I) and a second one peaking at $400 \mathrm{~nm}$ (II) with an intensity which is $17 \%$ higher than that of band I. It resembles the spectrum of the mononucleotide dGMP cation, ${ }^{[5]}$ also shown in Figure 1 , in which, however, the relative intensity of band II is $35 \%$ more intense than band I. Going from $\mathbf{A}^{+}$to $\mathbf{P}^{+}$, the spectrum exhibits remarkable changes: band I shifts clearly to longer wavelengths, while the intensity of band II further decreases.

The structural and electronic properties of the neutral and cationic species were then explored at the QM/MM (exploiting the $\mathrm{ONIOM}^{[8]}$ procedure as implemented in Gaussian09 ${ }^{[9]}$ ) and full QM levels using the crystal structure of $\mathbf{P}$ and $\mathbf{A}$ as reference. ${ }^{[6,7]}$ When included in the calculations, the phosphodeoxyribose backbone was always treated at the MM level with the AMBER parm96.dat ${ }^{[10]}$ force field. In the case of $\mathbf{A}$, for which the three tetrads are not topologically equivalent, we used only two computational models: A3T, sketched in Figure $2(\mathrm{QM} / \mathrm{MM}$ calculations with three tetrads in the $\mathrm{QM}$ part) and $\mathbf{A 3 T}_{\mathbf{b}}$ (full QM calculations including only the bases). A larger number of computational models were used for $\mathbf{P}$, which is bigger than A but contains topologically equivalent tetrads. Thus, at the QM/MM level we studied several models differing in the number of tetrads included in the $\mathrm{QM}$ region (P2T, P3T, P4T), the location of the considered tetrads (inner or external) and the treatment of the metal cation in the central cavity (see below). In particular, model $\mathrm{P}^{2} \mathrm{~T}_{\mathbf{b}}$ (full QM calculations with two tetrads including only bases) was thoroughly explored. Our reference QM method was DFT with M052 $\mathrm{X}^{[5 b, 11]}$ functional, combined with the $6-31 \mathrm{G}(\mathrm{d})$ basis set. Test calculations were also performed using B3LYP, ${ }^{[12]}$ CAM-B3LYP ${ }^{[13]}$ and $\omega B$ 97X ${ }^{[14]}$ functionals and more extended basis sets (6-31+ $G(d, p))$. Solvent effects were included by the PCM model in both QM and QM/MM calculations. ${ }^{[15]}$ A critical extensive discussion of our computational approach, successfully applied in the study of UV-induced processes in DNA (including radicals $)_{,}^{[4 b, 16]}$ is reported in the Supporting Information.

Despite the small structural differences of the minima which result from all computational models used in the analysis, the electronic circular dichroism and absorption spectra computed for "neutral" A and P are in agreement with the experimental ones (see Supporting Information). The only significant difference is a uniform blue-shift of the computed spectra, which, besides possible inaccuracies of our electronic calculations, is due to the lack of vibrational and thermal effects. ${ }^{[17]}$ In order to account for this shift and to allow an easier comparison with the experimental spectra, we decided to shift the computed absorption energies by $0.50 \mathrm{eV}$ (unshifted spectra are given in the Supporting Information). This value provides a good agreement between the computed and the experimental spectra of
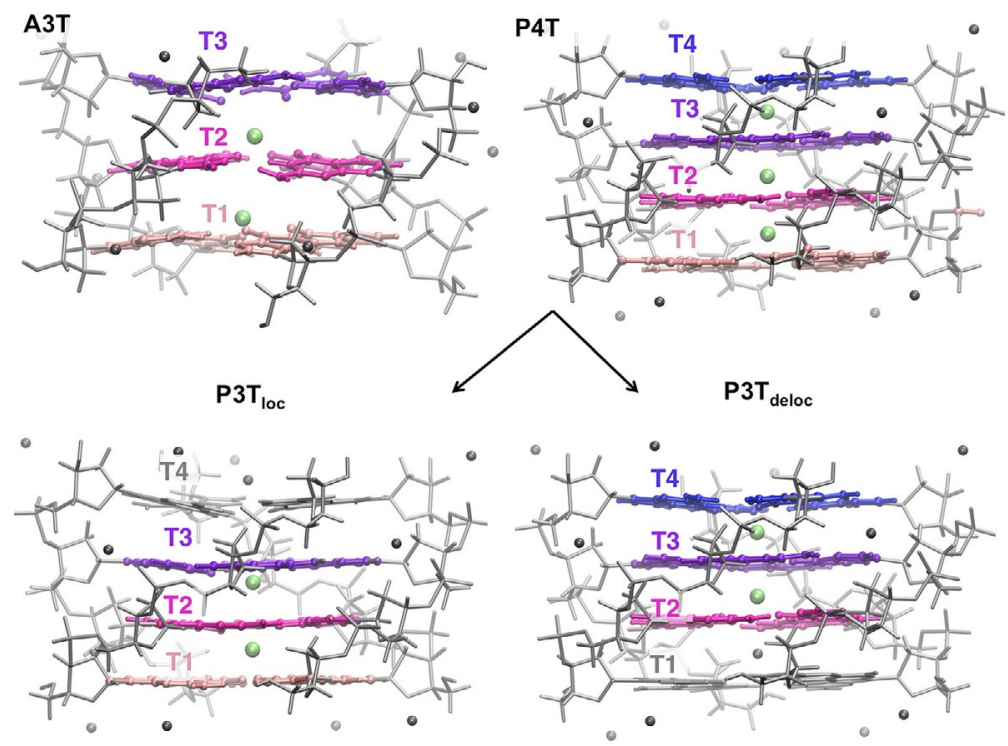

Figure 2. Systems studied at the QM/MM level for $\mathbf{A}$ and $\mathrm{P}$. Balls and sticks represent the QM parts and tubes the MM parts. Inner QM-Na ${ }^{+}$are represented in green balls, whereas $\mathrm{MM}-\mathrm{Na}^{+}$are shown in grey balls. Models studied at the $\mathrm{QM}$ level: $\mathbf{A 3 T}_{\mathbf{b}}\left(\mathbf{T} \mathbf{1}+\mathbf{T} \mathbf{2}+\mathbf{T} \mathbf{3}+2 \mathrm{Na}^{+}\right)$and $\mathbf{P} \mathbf{2} \mathbf{T}_{\mathbf{b}}\left(\mathbf{T} \mathbf{1}+\mathbf{T}_{2}+2 \mathrm{Na}^{+}\right)$. 
guanine cation (see Supporting Information). ${ }^{[18]}$ For the cationic G4, we started our analysis with $\mathbf{A}^{+}$, which has an experimental spectrum similar to that of the free dGMP cation. Our calculations on $\left[\mathrm{ABT}_{\mathrm{b}}\right]^{+}$and $[\mathrm{A} 3 \mathrm{~T}]^{+}$indicate that the hole is essentially localized over a single guanine, located in the external (T3) and internal (T2) tetrads, respectively (Figure 2). The computed absorption spectrum reproduces the main features of the experimental spectrum and, in particular, the relative intensities of bands I and II (Figure $3 \mathrm{a}$ ). ${ }^{[\mathrm{bb}]}$

Hole localization is also predicted for $[\mathrm{P4T}]^{+}$, in which a single base bears an excess of charge $\delta_{\mathrm{q}}=0.74 \mathrm{a}$.u. The corresponding guanine adopts a geometry typical of the free guanine cation, whereas the other guanines conserve the geometry found for the free neutral guanine. Subsequently, we used smaller models, and, hence, more affordable from a computational point of view, in order to explore hole localization in $\mathbf{P}$ in a more complete way. Calculations on $[\mathrm{P} 2 \mathrm{~T}]^{+}$indicate also hole localization independently of whether inner or external tetrads are described at the QM level (see Supporting Information). For the $[\mathrm{P} 3 \mathrm{~T}]^{+}$model, however, both localized and delocalized minima were obtained depending on the starting geometry for the cation optimization (see below). A similar picture emerges from the study of $\left[\mathrm{P}^{2} \mathrm{~T}_{\mathrm{b}}\right]$. When starting from the $\mathrm{PCM} / \mathrm{M} 052 \mathrm{X}$ optimized $\left[\mathrm{P}^{2} \mathrm{~T}_{\mathrm{b}}\right]$ minimum, geometry optimization of $\left[\mathrm{P}_{2} \mathrm{~T}_{\mathrm{b}}\right]^{+}$predicts that the hole is almost perfectly delocalized over two guanines belonging to two different tetrads $\left(\left[\mathrm{P2T}_{\mathrm{b}}\right]^{+}{ }_{\text {deloc }}\right)$. In contrast, when starting from the stacking arrangement experimentally determined for $\mathbf{P}_{1}^{[7]}$ geometry optimization of $\left[\mathrm{P}^{2} \mathrm{~T}_{\mathrm{b}}\right]^{+}$leads to a minimum with the hole localized on a single guanine, hereafter $\left[\mathrm{P}^{2} \mathrm{~T}_{\mathrm{b}}\right]^{+}{ }_{\text {loc }}$ which is more stable by ca. $0.3 \mathrm{eV}$ than $\left[\mathrm{P}^{2} \mathrm{~T}_{\mathbf{b}}\right]^{+}$deloc. At this stage, we have

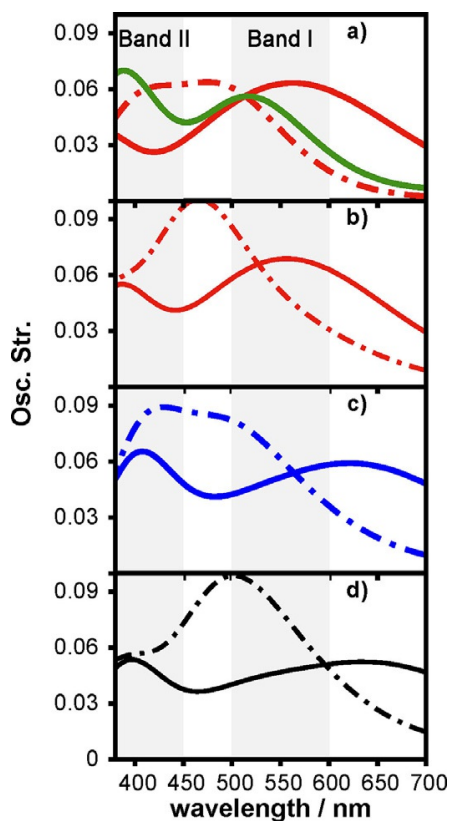

Figure 3. Computed absorption spectra for different models and different functionals. a) $[\mathrm{A} 3 \mathrm{~T}]^{+}$(green), $[\mathrm{P} 3 \mathrm{~T}]^{+}{ }_{\text {loc }}$ (red, dashed) and $[\mathrm{P} 3 \mathrm{~T}]^{+}{ }_{\text {deloc }}$ (red,

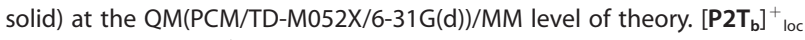
(dashed) and $\left[\mathrm{P2T}_{\mathrm{b}}\right]^{+}$deloc (solid) according to b) PCM/TD-M052X, c) PCM/TDCAM-B3LYP and d) PCM/TD- $\omega$ B97XD calculations. reached an important conclusion: for cationic parallel G4 structures, minima with different degrees of hole delocalization are possible.

As a next step, we investigated the effects which influence the localization/delocalization equilibrium in P. For example, we found that symmetry effects, connected to the position of the inner cations, are key factors in modulating hole delocalization (Table SI-2). When the neutral species PT3 is optimized starting from the crystal structure, where the inner $\mathrm{Na}^{+}$ions are not symmetric with respect to the three tetrads (PT3 ${ }_{\text {loc }}$ Figure 2), our calculations provide hole localization. On the contrary, when starting from structures where the two $\mathrm{Na}^{+}$ ions are symmetrically "sandwiched" between the tetrads, hole delocalization is found (PT3 deloc, Figure 2). Furthermore, test calculations on $\left[\mathrm{P}^{2} \mathrm{~T}_{\mathrm{b}}\right]^{+}{ }_{\text {loc }}$ and $\left[\mathrm{P2}_{\mathrm{b}} \mathrm{T}^{+}{ }_{\text {deloc }}\right.$ (Table SI-1) show that closer stacking between bases favors hole delocalization. We also stress that this equilibrium is not significantly affected by the selected density functional and basis set or by the polarity of the embedding medium (see Supporting Information). Finally, conformational fluctuations-the inclusion of which at the full QM level is not yet feasible for the $\mu$ s timescale-would likely favor hole localization.

All spectra computed for $\mathbf{P}^{+}$model systems (see Figure $3 \mathrm{a}$ and $\mathrm{SI}-6)$ are different from that of $\mathbf{A}^{+}$species. Both localized $\left([\mathrm{P3T}]^{+}{ }_{\text {loc }}\right)$ and delocalized $\left([\mathrm{P} 3 \mathrm{~T}]^{+}{ }_{\text {deloc }}\right)$ spectra show an inversion of the relative intensity of bands I and II compared to $\mathrm{A}^{+}$, the band I being more intense (Figure $3 \mathrm{a}$ ). On the other hand, the position of band I strongly depends on hole localization in $\mathbf{P}^{+}$(Figure $3 \mathrm{a}$ ). For $[\mathrm{P} 3 \mathrm{~T}]^{+}{ }_{\text {loc }}$ band $\mathrm{I}$ is blue-shifted compared to $\mathrm{A}^{+}$, and almost coalesces with band II. In contrast, for $[\mathrm{P} 3 \mathrm{~T}]^{+}{ }_{\text {deloc }}$ the band $\mathrm{I}$ is red-shifted with respect to that of $\mathrm{A}^{+}$. The spectra computed for the model $\mathbf{P} \mathbf{2} \mathbf{T}_{\mathbf{b}}$ present similar trends (Figure $3 \mathrm{~b}$ and $\mathrm{SI}-6$ ), which are full confirmed by test calculations adopting CAM-B3LYP and $\omega$ B97XD functionals. These spectra, which are shown in Figure $3 \mathrm{~b}$, provide a similar picture of the effect of hole delocalization in $\mathbf{P}^{+}$, which leads in particular to a significant red-shift of band $\mathrm{I}$.

Comparison between Figures 1 and 3 a shows that only the computed spectra corresponding to delocalized species exhibit all features of the $\mathbf{P}^{+}$experimental spectra, thus providing a second important conclusion for our study. Both larger hole delocalization (band I shift) and different stacking arrangements (relative intensity of bands I and II) are responsible for the different spectrum of $\mathbf{P}^{+}$and $\mathbf{A}^{+}$. Our conclusions are confirmed by test calculations using the B3LYP functional, which overestimates delocalization effects, and thus predicts delocalization for $\mathbf{A}^{+}$(Figure SI-6). Also for this antiparallel structure, hole delocalization is indeed accompanied by a relative increase of the intensity of band I (Figure SI-6).

Our calculations allow full assignment of the differences observed in the experimental spectra of $\mathbf{P}^{+}$and $\mathbf{A}^{+}$(Figure 2) and unveil consistent trends, which do not depend on the adopted computational approach; they were verified for many systems of different size (up to 10 minima have been considered). Independently of the degree of delocalization, the spectrum of cationic $\mathbf{~} 4$ is affected by the presence of "neutral" guanines located close to the electron hole. On one hand, 
transitions with predominant charge transfer (CT) character, involving the hole transfer from the guanine bearing the positive charge towards close lying bases, are present in both $\mathrm{A}^{+}$and $\mathbf{P}^{+}$. On the other hand, the different stacking arrangement in $\mathbf{P}$ and $\mathbf{A}$ is responsible for the spectral differences found in the case of localized holes in these G4. In particular, the stabilization of the bright state, $\pi \pi^{*}{ }_{2}\left(\mathrm{G}^{+} \rightarrow \mathrm{G}^{+*}\right.$, Figure $\mathrm{SI}-7$ and SI-8), for parallel arrangements accounts for the larger intensity of band $\mathrm{I}$ in the $\mathrm{P}^{+}$spectrum compared to that of $\mathrm{A}^{+}$. In addition, if the hole is delocalized, this electronic transition acquires partial CT character ( 0.17 a.u.) between the guanines sharing the hole (Figure SI-8 and SI-9). The mixed $\pi \pi_{2}{ }_{2} / \mathrm{CT}$ character precisely explains the red-shift of the band $\mathrm{I}$.

Our joint experimental and computational work has brought several new insights regarding hole transport in DNA. ${ }^{[19]}$ We provide evidence for the first time that electron holes may be delocalized in four-stranded structures; this phenomenon is strongly modulated by the G4 topology, being clearly favored by parallel arrangements. Hole delocalization in such structures is controlled by both conformational factors and the position of metal cations; its importance in charge migration has been highlighted. ${ }^{[19 e, 20]}$ More importantly, we identified the spectral fingerprint of delocalized holes, analyzing the associated electronic transitions. We showed that the effect of topology is not limited only on the spectra of delocalized holes but is also extended to those of localized ones. This impact is much more pronounced compared to that reported for the spectra neutral G4. ${ }^{[21]}$ Although electron holes in DNA have been treated quantum mechanically, ${ }^{[22]}$ no correlation has been established so far with their electronic absorption spectra. Yet, the knowledge of their spectral fingerprint could be very useful for distinguishing them in ultrafast transient experiments where other transient species potentially absorb. ${ }^{[23]}$ Our approach, based on photoionization by low energy UV light and QM calculations, provides precisely a tool that could be proved valuable for direct observation of electron holes in DNA.

\section{Acknowledgements}

The authors thank the CNR (Progetto Bilaterale CNR/CNRS PICS 2015), Université Paris Saclay (program D'Alembert 201610751), French Agency Research Grant (ANR-12-BS08-0001-01) and LABEX-PALM (OSPEG project) for financial support. This work was performed using HPC resources from GENCI-IDRIS (Grant 2017-A0030810262).

\section{Conflict of interest}

The authors declare no conflict of interest.

Keywords: absorption spectra - cations - DNA • G-
quadruplexes - UV light

[1] a) S. P. Liu, S. H. Weisbrod, Z. Tang, A. Marx, E. Scheer, A. Erbe, Angew. Chem. Int. Ed. 2010, 49, 3313-3316; Angew. Chem. 2010, 122, $3385-$ 3388; b) S. Delaney, J. K. Barton, Biochemistry 2003, 42, 14159-14165; c) J. Choi, A. Tanaka, D. W. Cho, M. Fujitsuka, T. Majima, Angew. Chem Int. Ed. 2013, 52, 12937-12941; Angew. Chem. 2013, 125, 13175-13179; d) A. K. Thazhathveetil, M. A. Harris, R. M. Young, M. R. Wasielewski, F. D. Lewis, J. Am. Chem. Soc. 2017, 139, 1730-1733; e) J. Y. Wu, Z. Y. Meng, Y. P. Lu, F. W. Shao, Chem. Eur. J. 2017, 23, 13980-13985.

[2] a) E. Fouquerel, J. Lormand, A. Bose, H. T. Lee, G. S. Kim, J. F. Li, R. W. Sobol, B. D. Freudenthal, S. Myong, P. L. Opresko, Nat. Struct. Mol. Biol. 2016, 23, $1092-1100$; b) A. M. Fleming, C. J. Burrows, Chem. Res. Toxicol. 2013, 26, 593-607.

[3] G. I. Livshits, A. Stern, D. Rotem, N. Borovok, G. Eidelshtein, A. Migliore, E. Penzo, S. J. Wind, R. Di Felice, S. S. Skourtis, J. Carlos Cuevas, L. Gurevich, A. B. Kotlyar, D. Porath, Nat. Nanotechnol. 2014, 9, 1040-1046.

[4] a) A. Banyasz, T. Ketola, A. Muñoz-Losa, S. Rishi, A. Adhikary, M. D. Sevilla, L. Martinez-Fernandez, R. Improrta, D. Markovitsi, J. Phys. Chem. Lett. 2016, 7, 3949-3953; b) A. Banyasz, L. Martinez-Fernandez, C. Balty, M. Perron, T. Douki, R. Improta, D. Markovitsi, J. Am. Chem. Soc. 2017, 139, 10561 -10568; c) A. Banyasz, T. Ketola, L. Martínez-Fernández, R. Improta, D. Markovitsi, Faraday Discuss. 2018, 207, 181-197.

[5] a) L. P. Candeias, S. Steenken, J. Am. Chem. Soc. 1989, 111, 1094-1099; b) L. Wu, K. Liu, J. Jie, D. Song, H. Su, J. Am. Chem. Soc. 2015, 137, 259266.

[6] Y. Wang, D. J. Patel, Structure 1993, 1, 263-282.

[7] G. Laughlan, A. I. Murchie, D. G. Norman, M. H. Moore, P. C. Moody, D. M. Lilley, B. Luisi, Science 1994, 265, 520.

[8] S. Dapprich, I. Komaromi, K. S. Byun, K. Morokuma, M. J. Frisch, J. Mol. Struct. 1999, 461, $1-21$.

[9] Gaussian 09, Revision A.1, M. J. Frisch, G. W. Trucks, H. B. Schlegel, G. E. Scuseria, M. A. Robb, J. R. Cheeseman, G. Scalmani, V. Barone, B. Mennucci, G. A. Petersson, H. Nakatsuji, M. Caricato, X. Li, H. P. Hratchian A. F. Izmaylov, J. Bloino, G. Zheng, J. L. Sonnenberg, M. Hada, M. Ehara, K. Toyota, R. Fukuda, J. Hasegawa, M. Ishida, T. Nakajima, Y. Honda, O. Kitao, H. Nakai, T. Vreven, J. A. Montgomery, Jr., J. E. Peralta, F. Ogliaro, M. Bearpark, J. J. Heyd, E. Brothers, K. N. Kudin, V. N. Staroverov, R. Kobayashi, J. Normand, K. Raghavachari, A. Rendell, J. C. Burant, S. S. Iyengar, J. Tomasi, M. Cossi, N. Rega, J. M. Millam, M. Klene, J. E. Knox, J. B. Cross, V. Bakken, C. Adamo, J. Jaramillo, R. Gomperts, R. E. Stratmann, O. Yazyev, A. J. Austin, R. Cammi, C. Pomelli, J. W. Ochterski, R. L. Martin, K. Morokuma, V. G. Zakrzewski, G. A. Voth, P. Salvador, J. J. Dannenberg, S. Dapprich, A. D. Daniels, Ö. Farkas, J. B. Foresman, J. V. Ortiz, J. Cioslowski, D. J. Fox, Gaussian, Inc., Wallingford CT, 2009.

[10] W. D. Cornell, P. Cieplak, C. I. Bayly, I. R. Gould, K. M. Merz, D. M. Ferguson, D. C. Spellmeyer, T. Fox, J. W. Caldwell, P. A. Kollman, J. Am. Chem. Soc. $1995,117,5179-5197$.

[11] Y. Zhao, N. E. Schultz, D. G. Truhlar, J. Chem. Theory Comput. 2006, 2, $364-382$.

[12] A. D. Becke, J. Chem. Phys. 1993, 98, 5648.

[13] T. Yanai, D. P. Tew, N. C. Handy, Chem. Phys. Lett. 2004, 393, 51-57.

[14] J.-D. Chai, M. Head-Gordon, Phys. Chem. Chem. Phys. 2008, 10, 66156620.

[15] a) S. Miertus, E. Scrocco, J. Tomasi, Chem. Phys. 1981, 55, 117-129; b) J. Tomasi, B. Mennucci, R. Cammi, Chem. Rev. 2005, 105, 2999-3093.

[16] a) R. Improta, Chem. Eur. J. 2014, 20, 8106-8115; b) M. Deiana, B. Mettra, L. Martinez-Fernandez, L. M. Mazur, K. Pawlik, C. Andraud, M. Samoc, R. Improta, C. Monnereau, K. Matczyszyn, J. Phys. Chem. Lett. 2017, 8, 5915-5920.

[17] F. J. Avila Ferrer, J. Cerezo, E. Stendardo, R. Improta, F. Santoro, J. Chem. Theory Comput. 2013, 9, 2072-2082.

[18] Y. Rokhlenko, J. Cadet, N. E. Geacintov, V. Shafirovich, J. Am. Chem. Soc. 2014, 136, 5956-5962.

[19] a) J. C. Genereux, J. K. Barton, Chem. Rev. 2010, 110, 1642-1662; b) K Kawai, T. Majima, Acc. Chem. Res. 2013, 46, 2616-2625; c) A. CapobianCo, T. Caruso, A. M. D'Ursi, S. Fusco, A. Masi, M. Scrima, C. Chatgilialoglu, A. Peluso, J. Phys. Chem. B 2015, 119, 5462-5466; d) N. Renaud, M. A. Harris, A. P. N. Singh, Y. A. Berlin, M. A. Ratner, M. R. Wasielewski, F. D. Lewis, F. C. Grozema, Nat. Chem. 2016, 8, 1015-1021; e) S. Kanvah, J. Joseph, G. B. Schuster, R. N. Barnett, C. L. Cleveland, U. Landman, Acc. Chem. Res. 2010, 43, 280-287.

[20] a) Y. Zhang, R. M. Young, A. K. Thazhathveetil, A. P. N. Singh, C. Liu, Y. A Berlin, F. C. Grozema, F. D. Lewis, M. A. Ratner, N. Renaud, K. Siriwong, A. A. Voityuk, M. R. Wasielewski, D. N. Beratan, J. Phys. Chem. Lett. 2015 6, 2434-2438; b) E. Beall, S. Ulku, C. Liu, E. Wierzbinski, Y. Zhang, Y. Bae, 
P. Zhang, C. Achim, D. N. Beratan, D. H. Waldeck, J. Am. Chem. Soc 2017, 139, 6726-6735; c) M. Zarea, Y. Berlin, M. A. Ratner, J. Chem. Phys. 2017, 146, 114105.

[21] A. I. Karsisiotis, N. M. Hessari, E. Novellino, G. P. Spada, A. Randazzo, M. W. da Silva, Angew. Chem. Int. Ed. 2011, 50, 10645-10648; Angew. Chem. 2011, 123, 10833-10836.

[22] a) A. Capobianco, T. Caruso, A. Peluso, Phys. Chem. Chem. Phys. 2015 17, 4750-4756; b) A. Kumar, M. D. Sevilla, J. Phys. Chem. B 2011, 115, 4990-5000; c) M. Pavanello, L. Adamowicz, M. Volobuyev, B. Mennucci, J. Phys. Chem. B 2010, 114, 4416-4423; d) T. Kubar, U. Kleinekathoefer M. Elstner, J. Phys. Chem. B 2009, 113, 13107-13117; e) N. Renaud, Y. A. Berlin, M. A. Ratner, Proc. Natl. Acad. Sci. USA 2013, 110, 14867-14871; f) Y. A. Mantz, F. L. Gervasio, T. Laino, M. Parrinello, Phys. Rev. Lett. 2007 99, 058104; g) C. J. Lech, P. Anh Tuan, M.-E. Michel-Beyerle, A. A. Voityuk, J. Phys. Chem. B 2013, 117, $9851-9856$; h) P. B. Woiczikowski, T. Kubar R. Gutierrez, G. Cuniberti, M. Elstner, J. Chem. Phys. 2010, 133, 035103. [23] M. A. Harris, A. K. Mishra, R. M. Young, K. E. Brown, M. R. Wasielewski, F. D. Lewis, J. Am. Chem. Soc. 2016, 138, 5491-5494.

Manuscript received: June 25, 2018

Accepted manuscript online: July 23, 2018

Version of record online: September 13, 2018 